\title{
The Comparison of English Learning between Two Ethnic Groups
}

\author{
Ching-Ying Lin \\ Department of Applied English, National Pingtung Institute of Commerce, Pingtung, Taiwan \\ Yong-Ming Chen \\ Department of Applied English, National Pingtung Institute of Commerce, Pingtung, Taiwan
}

\begin{abstract}
This purpose of the study was to explore English learning in parental influences and learning motivation between Taiwanese and multiracial children in southern Taiwan. There were 459 fifth and sixth elementary school students herein; there were 390 Taiwanese children and there were 69 multiracial children. There were six research questions here, and the main research instrument was questionnaire. According to results, Taiwanese children had stronger motivation learning English than multiracial children did. Secondly, parents' expectations and English learning of Taiwanese children had higher value than multiracial children's. The result indicated that Taiwanese children had higher motivation and expectations of parents than multiracial children did. Therefore, the researcher suggested that multiracial children should be considered about their learning process and thoughts. Multiracial children's English learning was improved and they would be willing to learn English because they were understood.
\end{abstract}

Index Terms-Taiwanese children, multiracial children, English learning motivation, foreign parents, parents' involvement

\section{INTRODUCTION}

Marriages between Taiwanese and foreigners increased annually before 2002. The highest percentage reached approximately $31.86 \%$ in 2003 . But, multi-national marriages began to decrease gradually in 2004 . However, many foreigners had still come to Taiwan to get married in recent years. Their children grew up, and educated in Taiwanese school. The number of multiracial children had increased in Taiwan based on data from the Ministry of Education. The number of multiracial children was 26,627 in 2003, and 133,112 in 2009 based on the elementary school enrollment in Taiwan (Ministry of Education, 2010); the rise was fast. Therefore, people paid more attention on these parents who were from different cultural backgrounds in recent years. Based on the aforementioned situation, the Ministry of Education (2010), paid more attention to strengthen the literacy and communication skills for foreign spouses in Taiwan because of the increasing multiracial population in elementary and junior high schools. Hence, a succession of educational support could gradually immerse foreign spouses into Taiwanese society. The progress of foreign mothers' Chinese literacy could then help their multiracial children's learning and had a positive effect on their schoolwork. Cronnell (1985) mentioned that incorrect speaking might affect learning, similar to writing. The speaking of non-standard Mandarin by multiracial children's foreign parents might affect their language learning before entering into school.

English learning was very important because of the global trend. English learning in Taiwan started from the fifth grade in elementary school since 2001, and then from the third grade since 2005. Elementary school students were expected to understand 300 words in oral achievement and 180 words in spelling achievement from 1,200 English words of a basic vocabulary base (Ministry of Education, 2006). English learning played an important role in the elementary schools in Taiwan. However, according to Kao's (2006) and Yang's (2009) studies, multiracial children had a lot of difficulties in English learning. The multiracial children could not handle their regular subjects and another language.

\section{Statement of The Problem}

Some studies had suggested that multiracial children had learning difficulty with the English learning process (Cheng, 2008; Chiang, 2008; Kao, 2005). Kao's (2005) research on three English learning ethnic groups indicated that multiracial children were lower achievers. Cheng (2008) and Chiang (2008), from research on the Chinese spoken by children with Vietnamese mothers, demonstrated that some speaking problems were apparent. Different learning environments also led to different learning outcomes.

Above all, these researchers revealed a distinction of English learning between urban and rural areas. Multiracial children had many English learning problems especially experienced by multiracial children. The aforementioned researchers focused on first through third grade elementary school students. The researcher wanted to delve deeply into the English learning situations and perspectives of multiracial higher-grade elementary school students. 


\section{RESEARCH QUESTIONS}

1. Is there any significant difference between Taiwanese children and multiracial children in terms of their motivation?

2. What is the relationship between parental expectations and children's English performance?

\section{REVIEW OF LITERATURE}

\section{A. Multiracial Taiwanese Children's Learning}

One foreign spouse, Jin-Hui, Lin, mentioned that "our children are not what TV news report. They are not backward children. They are clever and cute so don't treat us unfairly, please.” (Huang, 2005). Conversely, some or most people might still treat multiracial children based on different stereotypes.

According to the Ministry of Education (2010), because of the increasing multiracial population in elementary schools and junior high schools, the government proceeded to strengthen foreign spouses' literacy and communication ability in Taiwan. Hence, a succession of educational opportunities could help foreign spouses to gradually immerse in Taiwanese society, and then the Chinese literacy progress of foreign mothers could effectively help to enhance multiracial children's learning outcome. It also indicated that there might be some problems in multiracial children's learning. In the studies by Chung and Wang (2004) and Chung, Wang and Chen (2006), the same problem was identified, that the performance of multiracial children's native language learning was not equal to that of Taiwanese children before entering elementary schools. In Tsai's study (2006), multiracial children performed more poorly in their study domains than Taiwanese children did. Tsai mentioned that multiracial children whose mothers could speak more fluent Chinese or always tutored their children and helped them with schoolwork, performed better than multiracial children whose mother could not speak fluent Chinese or seldom tutored children and helped them with schoolwork. That was why the government needed to create activities that could increase foreign spouses' literacy and communication ability; this policy might also enhance multiracial children's learning progress through their mother's indirect help.

Regarding the abovementioned different backgrounds, cultural and language factors caused foreign spouses some problems in tutoring or communicating with their children in Mandarin Chinese when helping them with their schoolwork. Chung el al. (2004) also claimed that foreign spouses could not participate in children's schoolwork due to limited Chinese literacy. Meanwhile, multiracial children's Chinese literacy still remained inadequate; therefore, their literacy still needed to be strengthened before entering elementary school.

Conversely, some studies indicated that no significant difference in learning outcomes existed among whole children (Hsieh, 2004; Hsieh, 2008). Hsieh (2004) revealed that multiracial children performed well in their schoolwork, and that their Chinese language skills were better than those of math. Hsieh (2008) also showed that although multiracial children were poor at algebra, they were not as poor at other aspects of math. This was surprising as people generally thought that multiracial children might not be good at schoolwork because they could be influenced by their foreign mothers. However, multiracial children still could do well in Chinese and math. Moreover, these studies were not focused on multiracial children's English learning.

In Taiwan, English is a Foreign Language (EFL). Different literacy backgrounds between parents and children might influence children's learning. Possibly, insufficient native language acquisition affected learning other languages. Studies also indicated that multiracial children performed poorly in English learning (Kao, 2006; Yang, 2009). In Kao's research (2006), there was a serious problem in multiracial children's English learning in rural areas. Therefore, not only background, but also environment, affected multiracial children's English learning. Yang (2009) explored the notion that multiracial children demonstrated achievement in English; they and Taiwanese children exhibited the same attitudes. Nevertheless, multiracial children's attitudes did not reflect on their English performance. Taiwanese children performed relatively well in English learning but had the same attitude as multiracial children.

The aforementioned studies revealed that whether multiracial children's learning was adequate or not, their education still deserved care and must be strengthened. Otherwise, different learning outcomes among multiracial children would persist. Location, gender and growth background were factors influencing learning.

\section{B. Motivation in the Learning Process}

Rifai (2010) mentioned that learners could try to gain knowledge of the second language because of their own motivation; there were several factors like parents, friends, social environments, etc, that might directly or indirectly influence learners' learning. Lau (2009) explained that when children were young, their thoughts were bright and positive. However, more and more they would understand what they might encounter in school and life, and their thoughts also changed gradually. Teenagers had already encountered problems in school and life, social pressures. The different ages caused different changes in motivation. Obviously, the environment really influenced the motivation-change of age differences. Young learners gradually understood whatever situation they encountered. Therefore, different factors created diverse motivation in learning variation. Integrative motivation and instrumental motivation were usually discussed in relation to language learning. Rifai (2010) also explained that the instrumental motivation meant that learners studied languages as tools to accomplish their goals for succeeding in tests or work, 
external enforcement; integrative motivation meant that learners were willing to connect with, or had curiosity about, others, wanting to be immersed in different environments and to communicate with a variety of people. Instrumental motivation referred to students' studying because of an external enforcement, like passing tests.

Several studies mentioned that integrative motivation was stronger than instrumental motivation based on Gardner's study. However, Mori (2004) indicated that the research showed that instrumental motivation was helpful to gain proficiency information, while integrative motivation was not. Schmidt, Boraie and Kassabgy's study indicated that the language Egyptian learners who used in the classroom learning environment could not be suitable for Gardner's Model. ESL and EFL involved totally different social environments. ESL learning could occur inside and outside the classroom, while EFL learning occurred in the classroom. ESL learners had the chance to interact with others who also spoke English outside the classroom, in addition to the classroom, as they needed to be able to communicate with people in English. Nevertheless, EFL learners studied foreign languages because of the educational policy of the government. Learners did not need to use foreign languages outside the classroom because they still used their mother tongue. Clément, Dörnyei and Noels (1994) found that learners' motivation needed to relate to where they lived, or their language learning would only be academic. The social viewpoints provided a kind of criterion on what ways learners should study in order to receive high scores. In Taiwan, students only learned to receive better scores on tests, called high achievement. For this reason, learners might study foreign languages in the classroom for tests. Outside of a formal study environment, learners still used their native language. Wu and Wu (2008) mentioned that English as a Foreign Language (EFL) was regarded as the one curriculum at school for test study purposes, but not for life using purpose in most of Asia, like Taiwan. Thus, learners faced the learning environment at the moment and they also were influenced by learning motivation. In the EFL environment, foreign languages seemed to be regarded as instrument tools for the future life in Taiwan, and the advantages included having a good job, excellent scores on tests, etc, instrumental motivation. Verma (2005) commented that instrumental motivation offered skilled English people the chance to get many business positions, but it was just not at all helpful in learners' learning process. English used for jobs was a motivation to learn a foreign language. Although integrative motivation was a factor in second language learning, it was not absolutely required in foreign language learning. However, the instrumental motivation could be a strong learning factor when learners had a clear goal as mentioned above.

The people around the world who learned languages as L2 learning in foreign language environments aimed at becoming capable of communicating with others who spoke different languages; therefore, integrative motivation was not just for fitting into the society, but also as a tool for communication, which was why the Gardnerian conclusion was questioned (Kormos and Csizér, 2008). Although integrative motivation was a crucial element in learning a second language, English was indeed regarded as offering the ability to communicate with people who spoke different first languages around the world. English learning was not only for surviving environments but also to communicate with people. Based on different environments between ESL and EFL, intrinsic motivation stimulated learners to confront problems or to catch their interests related to learning foreign languages, and this would motivate their learning attitude, which differed from extrinsic motivation (Kang, 2000).

Intrinsic motivation was linked to learners' minds to study foreign languages, but extrinsic motivation forced learners' behavior: to study foreign language from outside factors (Horn, 1991; Joosten, Bundy, \& Einfeld, 2009). Rewards could stimulate learners' motivation (Elbel \& Horton, 1983; Horn, 1991). EFL learners acquired foreign languages in class through the instructor's activities, and these game activities motivated learners competitively. Elbel \& Horton (1983) mentioned that based on current research, prizes could not substitute for worth or rank of activities in the learning process. The prize factor could not be a principal for learning activities. Rewards were just a tool to make learners gain language knowledge effectively, so instructors needed to emphasize how to lead learners and what learners gained from activities. Moreover, Lumsden (1994) also remarked that teachers played important roles in learners' learning process, as in using interesting activities and in motivating learners' psychologically and educationally to satisfy learners' requirements.

Teachers at school should not be neglected because they were children's second educators after parents. In the long-term education process, teachers, at least, were children's mentor for knowledge-learning. In Kang's (2000) study, in regard to extrinsic motivation, learners' achievement might be influenced by educators' attitude; i.e., exterior factors stimulated learners' motivation. Thus, exterior factors affected learners' motivation during their learning process. Learners could be forced to learn by the external pressure of their teachers or school policy. As mentioned above, instructors or policy-makers needed to be careful about motivating learners' thirst for knowledge.

Wigfled (1994), citing Nicholls' suggestion, stated that motivation and appreciation of school affected the achievements of young learners. As children grew older, they gradually changed their perspectives. Wigfled also mentioned that children's ages would make their production and decision in regards to different activities change, because each child had obtained a variety of learning process as they grew up. This offered an opportunity for teachers and family members to increase learners' (children's) intrinsic motivation in the learning process while their minds gradually matured. The personal characteristics or thoughts also influenced their learning progress. Horn (1991) suggested that intrinsic motivation would be influenced by good feedback, an external force. Intrinsic motivation concerned a person's inside motive force to learn. It was different from extrinsic motivation in which motivation was an external source. Seven \& Engin's (2008) research pointed out that a strong sense of right attitude related to reading, was 
a strong factor stemming from intrinsic motivation. The relationship between reader and contexts, how much readers were interested in contexts, the number of times and the quantities readers read were influenced by intrinsic motivation. Accordingly, when EFL young learners were motivated by external factors and internal-arousing factors, and they could learn effectively. Long-term learning and life-time learning might result.

\section{Parental Involvement in Children's Learning Process}

Researches proven that parents' and family members' involvement in children's learning process could be key factors (Gonzalez-DeHass, Willems, \& Holbein, 2005; Peña, 2000; Tice, 1998); their actions or verbal behaviors influenced children directly or indirectly. Relatively, parents' role was very important in their children's educational process. Unfortunately, there were some cases in which the children might not be brought up by parents, and raisers could be grandparents or close relatives. However, these people role-play as parents and therefore affected children (learners). Sattes (1989) commented that not only parents, but also educators and people around children influenced children's learning before entering elementary schools; the advantages in children's learning process were maintained after senior high school. That above pointed out that it was advantageous toward children's schoolwork when parents were serious about their children education. What is more, children's success or failure in scholastic achievement could be influenced by parents' efforts and involvement. Some research indicated that parents who were serious and in children's schoolwork benefited children's learning (Sattes, 1989). In Asia, people generally equated success with the schoolwork with the future success; i.e., studying well and getting great scores were emphasized in children's learning, especially while children were under twelve-years of age. Tam \& Chan (2009) noted that some studies showed that children's learning process was directly related to Chinese parents' interference, as revealed in some research on children's education and parents' consideration. Apparently, parents' intervention was connected with the learning outcome and growth; when children knew that someone kept an eye on them, they would be cautious in dealing with their schoolwork in order to avoid reproach from parents. Children understood consciously that parents participated in their schoolwork and parents recognized the mistakes made working on homework. A series of involvement actions were used to strengthen children's learning skills.

In Jones' (2009) study, the disadvantaged socio-economic family might not be able to participate in and support their children's school life, a situation which educators must accept. The parents' status influenced their ability to assist children's assignments (Tam and Chan 2009). Maybe these lower status parents needed to work more, lacked the time to take care of schoolwork, or their knowledge background was insufficient to enhance their children's learning quality. Nevertheless, parents were able to express strong emotion and positive attitude on the learning outcome. Gonzalez-DeHass, Willems, \& Holbein (2005) mentioned that children's educational achievement and positive attitudes toward schools would be strengthened by parents' assistance. Children's strong motivation for learning was influenced and strengthened from parents' affective support. All involved behavior was good for help in the learning process, and this behavior would affect children's intrinsic development in a positive way. Learners' ability and motivation correlated with influences on children's education and the accomplishment of parents (Gonzalez-DeHass, Willems, \& Holbein, 2005). Accordingly, children's evolution was influenced toward successful learning by parents' positive involvement.

Cooperative action was much better than individual action; hence, parental involvement was needed to assist their children with schoolwork. Cooperation between parents and school was the one factor in the learning process. Carison (1991) mentioned that there could be some interaction shared between parents and schools which could make parents' participation in children's learning goals come true. The common goals of parents and schools could help them make plans effectively for children. Parents knew there were ideas from schools that strengthened children's learning and school personnel showed parents their educational plans. Children's school learning could not be devoid of parental participation at all (Carison, 1991). As a result, cooperation could be carried out, and the schools could also show parents how they could help to each other. Peña (2000) said that educators needed to understand their viewpoints to become a team. The study revealed that the plan could be done well when the parents were involved; parents' participation inspired children to participate in class. Studies proved that parental involvement had its function in children's learning. Schools also needed to provide timely assistance to parents so that they and the educators could cooperate in completing a whole learning process on the part of children. Corporation of schools and parents would greatly improve the children's education.

\section{Methods And PRocedures}

The participants were higher-grade elementary school students in southern Taiwan. The questionnaire method was used to explore research questions. A total of 459 fifth and sixth grade elementary school students comprising 390 Taiwanese children and 69 multiracial children participated in this research.

Instrumentation Used for the Study-The questionnaire was the main instrument in this research. The complete questionnaire comprised three parts: background information, learning motivation and parental involvement.

A. Background Information

Eight questions were asked for the basic background information of participants. In this part, the participants filled all the items. Moreover, this part would not be scored.

B. Learning Motivation 
There were thirty-nine items in the part two of the questionnaire, and it was divided into two categories including learning attitude and learning motivation. Items 1 to 23 were under the motivation category (intrinsic domain for items 1 to 15 and extrinsic domain for items 16 to 23). Items 24 to 39 were under the attitude category. These questions related to students' English learning situation at school and at home. Scores in the part two were based on a five-point Likert Scale equated with a score. Each response was to measure frequency: (a) strongly agree $=5$, (b) agree $=4$, (c) neutral $=3$, (d) disagree $=2$ and (e) strongly disagree $=1$.

C. Parental Involvement

In the part of three of this questionnaire, it focused on parental influence as well as parental involvement. There were 20 questions regarding students' English learning situation related to parental involvement at school and at home. Scores in the part three were based on a five-point Likert Scale equated with a score. Each response was to measure frequency: (a) always $=5$, (b) usually $=4$, (c) sometimes $=3$, (d) seldom $=2$ and (e) never $=1$.

Procedure of the Study-Contact, instruments, and data collection were discussed here. The final step was data analyses.

\section{A. Contact}

The researcher went to some elementary schools in Ping-Tung County, and met each main director of the schools. The purpose of this research was to explain to each director. Then, each of them allowed the researcher to conduct research at the respective schools.

\section{B. Instruments}

The researcher gave each director of participating schools the questionnaires. The researcher interpreted what the directors needed to be aware of during the questionnaire-filling process. In addition, the English teacher might help participants complete the questionnaire when participants had questions about some items. After that, the questionnaire was administered at each participating school and the researcher was told that the data of completing the questionnaire.

C. Data Collecting

The researcher went to school to collect all the questionnaires. The researcher also ensured that all the data were collected. Finally, the researcher appreciated the assistance of all the participating schools.

Data Analysis-The data analyses employ the SPSS system to calculate the statistics. The mean and the standard deviation (SD) calculation were used for research questions one to determine whether or not they were statistically significant. In addition, correlation coefficient (r) was used for research questions two. This calculation was for determining the relation between parental expectations and children's English education outcome.

\section{RESULTS}

There are two research questions: "Is there any significant difference between Taiwanese children and multiracial children in terms of their motivation?" "What is the relationship between parental expectations of children's English performance?"

A. Research Question 1: Is there any significant difference between Taiwanese children and multiracial children in terms of their motivation?

TABLE 1

\begin{tabular}{lllll}
\multicolumn{7}{c}{ MEANS FOR INTRINSIC AND EXTRINSIC MOTIVATION AT SCHOOL AND AT HOME (N $=459)$} & Taiwanese children & Multiracial children \\
\hline \multirow{2}{*}{ Category } & Item & Whole group & Mean & 3.33 \\
\cline { 2 - 5 } & $1-15$ & 3.40 & 3.72 & 3.62 \\
\hline Intrinsic & $16-23$ & 3.71 & 3.50 & 3.36 \\
\hline Extrinsic & $1-7$ & 3.48 & 3.42 & 3.24 \\
\hline $\begin{array}{l}\text { Intrinsic } \\
\text { toward school }\end{array}$ & $8-15$ & 3.40 & 3.734 & 3.61 \\
\hline $\begin{array}{l}\text { Intrinsic } \\
\text { toward home }\end{array}$ & $16-20$ & 3.716 & 3.716 & 3.65 \\
\hline $\begin{array}{l}\text { Extrinsic } \\
\text { toward school }\end{array}$ & $21-23$ & 3.706 & & \\
\hline $\begin{array}{l}\text { Extrinsic toward } \\
\text { home }\end{array}$ & & & \\
\hline
\end{tabular}

Table 1 showed the means for intrinsic and extrinsic motivation of English learning at school and at home. The difference of the mean between these two groups was significantly higher for Taiwanese children comparing to multiracial children. Intrinsic and extrinsic motivation scores for Taiwanese children were higher in regard to school and home.

For whole group, extrinsic motivation was higher than intrinsic motivation; intrinsic motivation for school learning situation was higher than intrinsic motivation for home; and extrinsic motivation for school learning situation was higher than extrinsic motivation for home learning.

For Taiwanese children, extrinsic motivation was higher than intrinsic motivation; intrinsic motivation for school learning situation was higher than intrinsic motivation for home learning situation; and extrinsic motivation for school learning situation was higher than extrinsic motivation for home learning situation.

For multiracial children, extrinsic motivation was higher than intrinsic motivation; intrinsic motivation for school 
learning situation was higher than intrinsic motivation for home learning situation; and extrinsic motivation for home learning situation was higher than extrinsic motivation for school learning situation.

For whole group and the two different groups, their extrinsic motivation was stronger than intrinsic motivation. According to the results, external influences played an important role in these children's English learning.

TABLE 2

THE TOP FIVE MOTIVATION QUESTIONS AMONG TAIWANESE CHILDREN (N=390)

\begin{tabular}{|c|c|c|c|c|}
\hline Rank & Item & Statement & Mean & orientation \\
\hline 1 & 19 & My teacher assigns me English homework, so I have to hand it in in time. & 4.05 & Ex* \\
\hline 2 & 4 & I can finish homework in time after school. & 3.97 & In** \\
\hline 3 & 3 & I think learning English is helpful for me. & 3.96 & In \\
\hline 4 & 23 & To get a better job in the future, I need to learn English. & 3.80 & Ex \\
\hline 5 & 16 & All I want to do is get good scores in English. & 3.79 & Ex \\
\hline
\end{tabular}

Note. *Extrinsic motivation **Intrinsic motivation

TABLE 3.

THE TOP FIVE MOTIVATION QUESTIONS AMONG MULTIRACIAL CHILDREN (N=69)

\begin{tabular}{lllll}
\hline Rank & Item & Statement & Mean & orientation \\
\hline 1 & 19 & My teacher assigns me English homework, so I have to hand it in in time. & 3.96 & Ex* \\
\hline 2 & 3 & I think learning English is helpful for me. & 3.86 & In** \\
\hline 3 & 20 & I can't fall behind my classmates in English, so I try harder to learn it. & 3.74 & Ex \\
\hline 4 & 23 & To get a better job in the future, I need to learn English. & 3.72 & Ex \\
\hline 5 & 4 & I can finish my homework in time after school. & 3.71 & In \\
\hline
\end{tabular}

Two motivation items were the same for their English learning between these two groups based on Tables 2 and 3. They were item 19, rank one, and item 23, rank four, respectively. English teachers had an important impact on children's English learning. Learning English was crucial for what they could do in the future; this influenced them. Furthermore, although items 3 and 4 were in different ranks, they were also in the top five. These two questions were about intrinsic motivation. Taiwanese children were more compliant about completing their homework than multiracial children were. Items 16 and 20 involved different motivation for English learning for these two groups. Taiwanese children's item 20 was in rank six, and multiracial children's item 16 was in rank twelve. Most of items were in the top five but the mean of Taiwanese children was indeed higher than that of the multiracial children.

B. Research Question 2: What is the relationship between parental expectations of children's English performance?

TABLE 4

CORRELATION COEFFICIENT AMONG TAIWANESE AND MULTIRACIAL PARENTAL EXPECTATIONS $(\mathrm{N}=459)$

\begin{tabular}{|c|c|c|c|c|c|c|}
\hline 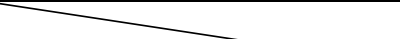 & \multicolumn{3}{|c|}{ Taiwanese children $(\mathrm{N}=390)$} & \multicolumn{3}{|c|}{ Multiracial children $(\mathrm{N}=69)$} \\
\hline & $\mathrm{r}$ & $\mathrm{p}$ & $\mathrm{r}^{2}$ & $\mathrm{r}$ & $\mathrm{p}$ & $\mathrm{r}^{2}$ \\
\hline Expectations and English learning & .762 & $.000^{*}$ & .581 & .642 & $.000 *$ & .412 \\
\hline
\end{tabular}

According to Table 4, The second research question explored the influences of parental expectations on children's English learning. For Taiwanese children, $r=.762,(\mathrm{sig})=.000<.05$, so it was a positive relationship. For $\mathrm{r}^{2}, 58 \%$ of the children variance predicted that Taiwanese children did what their parents expected on English learning. For multiracial children, $r=.642,(\mathrm{sig})=.000<.05$, so it was a positive relationship. For $\mathrm{r}^{2}, 41 \%$ of the children variance predicted that multiracial children did what their parents expected on English learning.

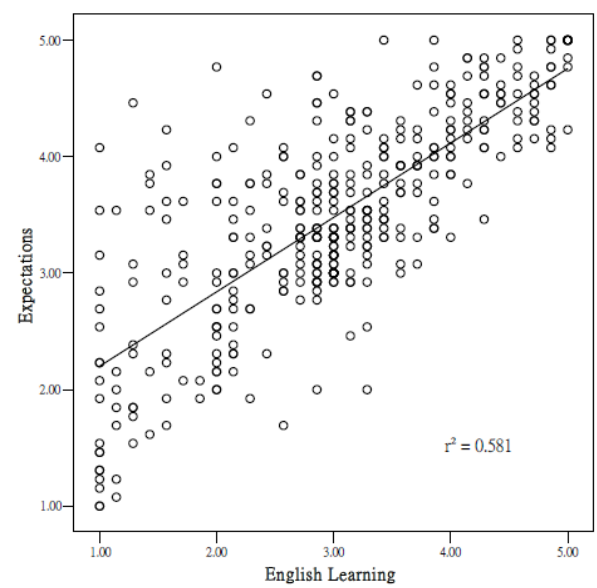

Figure 1. The r square between expectations and English Leaming among Taiwanese children.

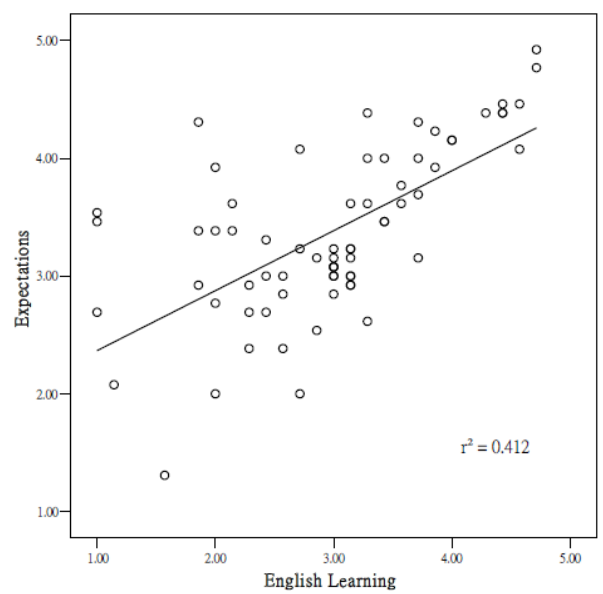

Figure 2. The $\mathrm{r}$ square between expect at ions and English Leaming among mult iracial children. 
According to Fig. 1, $\mathrm{r}^{2}$ was 0.581 , and approximately $58 \%$ percentage of Taiwanese children might follow this prediction, which was that these children would do something for their English learning when their parents had higher expectations concerning their children's learning process.

According to Fig. 2, $\mathrm{r}^{2}$ was 0.412 , and approximately $41 \%$ of multiracial children might follow this prediction, which was that these children would do something for their English learning when their parents had higher expectations concerning their children's learning process.

Based on Figs. 1 and 2, $\mathrm{r}^{2}$ of Taiwanese children obtained a higher value than multiracial children did because the relationship between parental expectations of children's English education in regard to Taiwanese children and the results were much stronger than those for multiracial children. It seemed that Taiwanese children's parents made a lot of effort for their children.

\section{CONCLUSIONS}

According to answers of research questions, there were two main results here. Firstly, these two groups' extrinsic motivation was higher than intrinsic motivation. There were similar motivation question ranks between these two groups, but Taiwanese children got higher mean in all motivation questions than multiracial children did. This result indicated that Taiwanese children had stronger motivation learning English than Taiwanese children did. These two groups might be influenced by different environments. What Clément, Dörnyei, and Noels (1994) mentioned was that learners' motivation needed to relate to where they live or their language learning was only academically-related (Clément, Dörnyei and Noels, 1994). Although multiracial children live in Taiwan, foreign parents might influence them indirectly. Secondly, parents' expectations and English learning of Taiwanese children had higher value than multiracial children's. Parents still played an important role in their children's learning. Parents' words and deeds influenced their children directly or indirectly. Tam \& Chan (2009) mentioned that some studies showed that children's learning process related to Chinese parents' interference, and these facts were revealed in research on children's education and parents' consideration. When parents gave their children high support and consideration, children did their best in regard to learning. Taiwanese children's and multiracial children's viewpoints were revealed herein. English learning was not only carried out in public and private schools, but also in cram schools in Taiwan. Motivation differs because of individual characteristics, family background, race, etc. Thus, learners might reach their goals if motivation was properly handled.

This research was based on a questionnaire instrument. All of the information was obtained by Taiwanese and multiracial children filling in blanks of questionnaire while they read every sentence statement. Learners included Taiwanese and multiracial children who participated in this research. Participants filled in blanks from every statement of the questionnaire. Therefore, the interview could be added to this research in order to gain more information. Thoughts of these two groups might be brought out from the deep interview process to make connections between the results of the questionnaire and interview. Scores of participants also could be referred. Family members were not included here because their thoughts were information, too. Schools included teachers and school members. Taiwanese and multiracial children were the main subjects. Teachers or school members who could complete the questionnaire of notions among these two groups also participated in the research. The interviews might be added, too. The district was limited to Ping-Tung County. People in different districts may have different views. The age range was between eleven to twelve years old and participants were fifth-grade and sixth-grade Taiwanese and multiracial children. Psychological growth could lead to different results. The influence of gender was the one factor omitted here; different genders might have different ways of doing things because of general social reactions, psychology, environment, peer influences, etc. Family members were not included here yet their views might provide information, too. The abovementioned pointed hinder the generalizability of the results

Parent backgrounds were different in the multiracial children group. This was important since different backgrounds might influence their thoughts. Language structure, culture background, and pattern of thoughts might be diverse because of people having lived in different countries. Plus, foreign parents could mix primary backgrounds with Taiwan backgrounds, making for a different pattern. Maybe multiracial children had different ideas from Taiwanese children, but their ideas needed to be respected, too. Besides, multiracial children's idea could be creative for education-promoting because pedagogies would better suit every unique child to gain knowledge. Deep interviews or open-ended questions could provide more information outside of the questions and make children's ideas or foreign parents' thoughts clearer. This is important with the increasing ethnicity in Taiwan.

In home environments, foreign parents have special identities in Taiwan. They came from different cultural backgrounds. Their children might also be affected by their foreign parents. However, the family could provide appropriate or even necessary assistance. For example, let multiracial children understand that they were not different. Only their parents cane from different countries. This attitude would inspire them learn about a variety of cultures. The real assistance of family was the basic element for multiracial children because they still went back their home towns. Therefore, the deep research might explore the home environments of the participants. Neighbors were counted into the research because they were sometimes involved in the multiracial children's life. These people could also answer the questionnaire. Furthermore, interviews and surrounding observations were explored to collect information regarding 
differences and similarities between Taiwanese children and multiracial children.

In school environments, students knew that multiracial children were different from themselves. Teachers might instruct all students that there were no differences because everyone lived here and studied here. There should be an effort in learning about other cultures. The immersion environments supplied a proper education. Moreover, in the school assembly, the school sometimes provided guidance on multicultural issues. So, teachers and the school itself cooperated together. Therefore, the deep research might explore school environments where these participants learned together. Teachers and school members were in one part of the research. Teachers and staffs were interviewed about children learning and performance. Classroom observations were used to include practical research to analyze the results.

In the national environment, the government was the policy-maker and its decision would influence what and how people thought of multicultural children. Maybe people still believed that foreign parents were foreigners in Taiwan because of their lack of knowledge toward the different cultural background of the parents. Up to the present, a number of people regarded these foreign parents as outsiders, especially foreigners from Southeast Asia. Southeast Asians were thought to have a son to carry on the family name in order to keep the family alive. In addition, Southeast Asian children were considered backward because their parents came from educationally backward countries. These parents experienced language problems during conversations with their children. Hence, multiracial children had learning problems because their learning development was not sufficient. Government needed to do help for foreign parents accommodate to Taiwan culture and to learn Mandarin and Taiwanese. Similarly, government also needed to guide Taiwan people to accept different external culture. Internal and external culture backgrounds might help all groups to understand and respect each other. Therefore, the deep research might explore the thoughts of people throughout the country in order to help steer the government in the right direction.

According to the results, multiracial children's performance was lower than Taiwanese children's. Their motivation led to much lower scores than Taiwanese children. Parents' expectations developed different degrees in English learning. Taiwanese children's parents had higher expectations that led to higher learning attitude and motivation. These two groups had different expectations toward English teachers' instructions. However, open-ended questions and interviews could be used here in order to collect deep information and made connections with the results of this research. Age, gender, and districts were divided into specific research in order to collect detailed data. Schools, family, and the whole of society could work together to help people from different cultural backgrounds. When every one could understand each other deeply, the general public was able to know how to help foreigners. Therefore, the general public would not regard foreigners as outsiders, but as part of the society.

\section{REFERENCES}

[1] Carison, C. G. (1991). Getting parents involved in their children's education. The Education Digest, 57(3), 10-12.

[2] Cheng, Y.-C. (2008). A study on phonological awareness of Vietnamese foreign Spouse's children in Taiwan (master's thesis). Retrieved from National Digital Library of Theses and Dissertations in Taiwan.

[3] Chiang, P.-J. (2008). An investigation on children's speech intelligibility of Vietnamese foreign spouses in Taiwan (master's thesis). Retrieved from National Digital Library of Theses and Dissertations in Taiwan.

[4] Chung, F.-C. \& Wang, K.C. (2005). An investigation of language, mental ability, and learning behavior development for children of foreign bride families. Educational Review, 23, 231-258.

[5] Chung, F.-C., Wang, K.C. \& Chen, Y.-L. (2006). A comparison study of language, mental abilities development, and learning behavior for children of foreign bride families in Pingtung. Bulletin of Educational Psychology, 37(4), 411-429.

[6] Clément, R., Dörnyei, Z. \& Noels, K. A. (1994). Motivation, self-confidence, and group cohesion in the foreign language classroom. Language Learning, 44(3), 417-448.

[7] Cronnell, B. (1985). Language influences in the English writing of third- and sixth-grade Mexican-American students. The Journal of Education Research, 78(3), 168-173.

[8] Elbel, J. \& Horton, I. P. (1983). A study of extrinsic V.S. intrinsic motivation in college students. Retrieved from ERIC database. (ED234320).

[9] Gonzalez-DeHass, A. R., Willems, P. P. \& Holbein, M. E. D. (2005). Examining the relationship between parental involvement and student motivation. Educational Psychology Review, 17(2), 99-123.

[10] Hsieh, H.-M. (2008). An investigation of the immigrant women's children of Yunlin county in mathematics performance - take the third grade students in the elementary school for example (master's thesis). Retrieved from National Digital Library of Theses and Dissertations in Taiwan.

[11] Kao, C.-H. (2006). English literacy proficiency of third grade elementary school students: A study on three ethnic groups in Pingtung County (master's thesis). Retrieved from National Digital Library of Theses and Dissertations in Taiwan.

[12] Horn, E. D. (1991). An argument for using intrinsic rather then extrinsic motivation, with specific suggestions for teachers. Retrieved from ERIC database. (ED355036)

[13] Huang, Y.-Y. (2005, November). New Taiwanese children - across the unfair vision. Common Wealth, 334, 144-151.

[14] Jones, C, (2009). Parental support and the attitudes of boys and girls to modern foreign languages. Language Learning Journal, $37(1), 85-97$.

[15] Joosten, A. V., Buddy, A. C. \& Einfeld, S. L. (2009). Intrinsic and extrinsic motivation for stereotypic and repetitive behavior. $J$ Autism Dev Disord, 39(3), 521-531.

[16] Kang, D. H. (2000). Motivation and foreign language learning in Korean EFL context. Retrieved from ERIC database. (ED442284) 
[17] Kormos, J. \& Csizér, K. (2008). Age-related differences in the motivation of learning English as a foreign language: Attitudes, Selves, and motivated learning behavior. Language Learning, 58(2), 327-355.

[18] Lau, K. L. (2009). Grade differences in reading motivation among Hong Kong primary and secondary students. British Journal of Educational Psychology, 79, 713-733.

[19] Lumsden, L. S. (1994). Student motivation. Retrieved from ERIC database. (ED369142)

[20] Ministry of Education. (2010). The overview of Mainland and the number of school children of foreign spouses. Retrieved from http://www.edu.tw/files/site_content/B0013/overview44.xls (accessed 12/05/2011). [21] Ministryof Education.
http://www.edu.tw/files/site_content/B0013/son_of_foreign_98.pdf(accessed22/06/2011).

[22] Missall, L. N., Mcconnell S. R., \& Cadigan, K. (2006). Early literacy development: Skill growth and relations between classroom variables for preschool children. Journal of Early Intervention, 29(1), 1-21.

[23] Mori, S. (2004). Significant motivational predictors of the amount of reading by EFL learners in Japan. Regional Language Centre Journal, 35(1), 63-81.

[24] Peña, D. C. (2000). Parent involvement: Influencing factors and implications. The Journal of Educational Research, 94(11), 42-54.

[25] Rifai, N. A. (2010). Attitude, motivation, and difficulties involved in leaning the English language and factors that affect motivation in learning it. Procedia Social and Behavioral Sciences, 2, 5216-5227.

[26] Sattes, B. (1989). Parental involvement in student learning. The Education Digest, 54(5), 37-39.

[27] Schellinger, S. B. (1994). Barriers to language acquisition in school- Age Mexican American children. Retrieved from ERIC database. (ED386912)

[28] Seven, M. A. \& Engine, A. O. (2008). Effective motivation in language learning. Retrieved from http://www.fatih.edu.tr/ hugur/study_hard/effective\%20motivation\%20in\%20language\%20learning.doc(accessed 10/01/2011).

[29] Tam, V. C. \& Chan, R. M. (2009). Parental involvement in primary children's homework in Hong Kong. The School Community Journal, 19(2), 81-100.

[30] Tice, T. N. (1998). Research spotlight. The Education Digest, 63(8), 41-44.

[31] Tsai, C.-C. (2006). The research on learning adaptation and scholastic achievement of foreign spouses' children (master's thesis). Retrieved from National Digital Library of Theses and Dissertations in Taiwan.

[32] Verma, M. H. (2005). Learner's attitude and its impact on language learning. Retrieved from http://147.8.145.43/clear/conference08/doc/handouts/verma\%20meenakshi\%20h_handout.pdf(accessed 22/06/2011).

[33] Wigfield, A. (1994). Expectancy-value the theory of achievement motivation: A developmental perspective. Educational Psychology review, 6(1), 49-78.

[34] Wu, W. V. \& Wu, P. N. (2008). Creating an authentic EFL learning environment to enhance student motivation to study English. Asian EFL Journal, 10(4), 211-226.

[35] Yang, Y.-F. (2009). The correlation of family factors to new immigrant children's English learning attitude and English learning achievement in Taoyuan County (master's thesis). Retrieved from National Digital Library of Theses and Dissertations in Taiwan

Ching-Ying Lin (Ed. D.) is an assistant professor in the Department of Applied English, National Pingtung Institute of Commerce, Pingtung, Taiwan. She got her doctoral degree from Texas A\&M university, U.S.A. Her research areas are TESOL/TEFL Methodology, Speech and Communication, Second Language Acquisition, Learning Strategy, TESOL/TEFL curriculum and Material Design.

Yong-Ming Chen was Dr. Lin's graduate student. He teaches English in Taiwan now. 